\title{
Amélia Paes de Andrade Travassos da Rosa
}

\author{
Amélia Paes de Andrade Travassos da Rosa
}

Jorge Fernando Soares Travassos da Rosa

Instituto Evandro Chagas/SVS/MS, Ananindeva, Pará, Brasil

Ser humano iluminado, detentora de rara inteligência e nobre coração, marcou sua passagem pelo campo da pesquisa, construindo pilares alicerçados em ideias diferenciadas, todas voltadas para a construção de um ramo da ciência que se apresenta atualmente de extrema importância para a saúde pública mundial: as arboviroses.

Amélia nasceu em 31 de dezembro de 1937, na cidade de Belém, estado do Pará, Brasil, e, desde muito cedo, ainda acadêmica do Curso de Farmácia da Universidade Federal do Pará, demonstrou aos mestres sua inclinação para a pesquisa científica, porquanto o interesse e a curiosidade na discussão de temas relacionados a essa área assim a revelavam e que se somava ao destacado e sempre impecável desempenho curricular.

Ao ingressar no Instituto Evandro Chagas (IEC), em janeiro de 1959, à época da presença da Fundação Rockfeller no Brasil, que mantinha um convênio com a Fundação Serviço Especial de Saúde Pública, Amélia foi premiada ao ser escolhida para trabalhar com os Drs. Ottis e Calixta Causey. Esses pesquisadores americanos vislumbraram, naquela jovem profissional, a semente fértil para que seus esforços, na implantação das pesquisas no campo da Virologia no IEC, não fossem descontinuados quando cessasse o período que dispunham para formar competência científica na Região Amazônica. Retornaram para os Estados Unidos confiantes no dever cumprido, cientes de que aquela cientista, por eles preparada, saberia honrar os ensinamentos e quiçá crescer exponencialmente à luz de novos conhecimentos que seguramente conquistaria pelos anos que se seguiriam. Estavam absolutamente certos.

Como pesquisadora, Amélia incorporou a mais importante característica de um profissional, trabalhando em nossa Região: a de ser essencialmente amazônida, por sua vocação e entusiasmo em pesquisar as peculiaridades dos vírus, especificamente os arbovírus da Amazônia. A dedicação que dispensou ao estudo sobre os arbovírus no IEC rendeu-lhe, em 40 anos, a identificação e a caracterização de quase duas centenas de diferentes vírus, em mais de 10.000 amostras isoladas de mosquitos, carrapatos, artrópodes e vertebrados, resultando na publicação de mais de 200 trabalhos científicos em revistas nacionais e internacionais; informações essas fornecidas pela

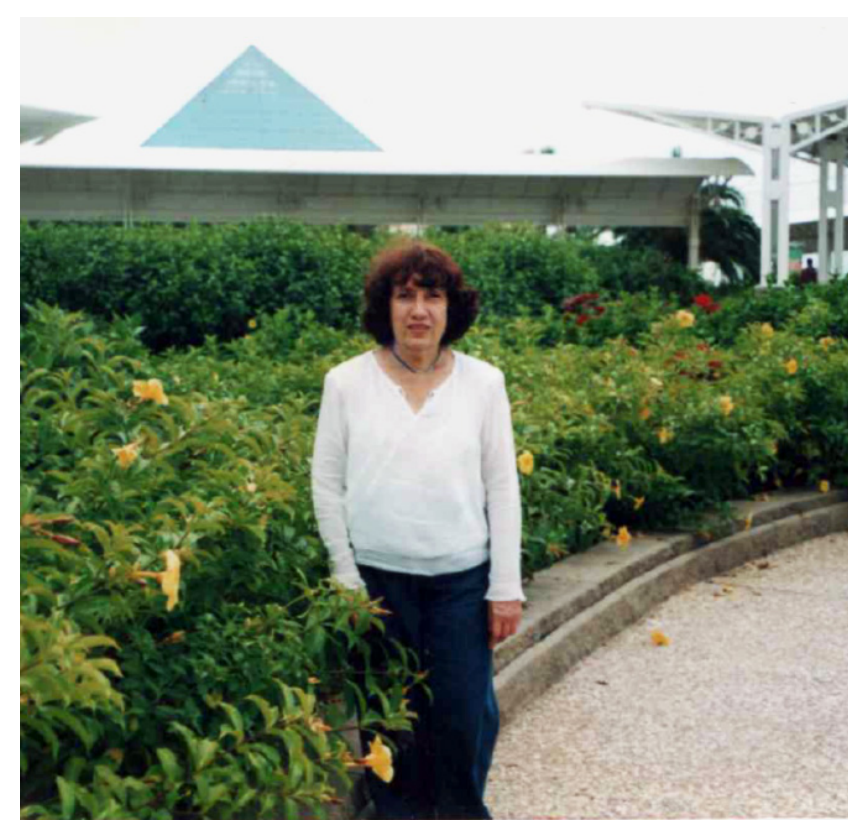

Amélia Paes de Andrade Travassos da Rosa (1937-2017).

própria cientista no artigo "The history of Arbovirology at Instituto Evandro Chagas, Belém, Pará, Brazil, from 1954 to 1998", publicado na Revista Pan-Amazônica de Saúde (2016; vol. 7 núm esp:61-70), e que representou parte importantíssima das investigações sobre a ecologia dos arbovírus. Complementarmente, foram realizadas centenas de inquéritos sorológicos em populações humanas e de animais silvestres para o estudo da dispersão desses vírus. Essa conquista foi fruto de um excelente trabalho de campo conduzido por equipes formadas sob a orientação dessa profissional. Desses vírus em relato, 36 estão associados a doenças em humanos e cinco são considerados de importância em saúde pública, como Dengue, Febre amarela, Oropouche, Mayaro e Rocio, sendo responsáveis por epidemias em zonas urbanas ou rurais, constituindo um risco à saúde de uma parcela representativa da população.

Como líder e chefe da Seção de Arbovirologia, formou pesquisadores, técnicos e auxiliares de pesquisa do IEC e de outras instituições, inclusive estrangeiras, que incorporaram o amor e a entrega pela pesquisa e que foram responsáveis por replicar os consolidados ensinamentos repassados por ela, sustentando a base de uma escola que pregou, fundamentalmente, o compromisso, a seriedade, a responsabilidade e a 
dedicação pela ciência. Deve-se enfatizar que nenhum dos resultados sob sua responsabilidade, tanto os relacionados à pesquisa quanto à rotina, foi refutado. Havia um lema em sua caminhada: "Há mais felicidade em dar do que em receber."; e isso norteava seu sempre produtivo trabalho, traduzido, obviamente, no repasse de conhecimentos sobre a área que tão bem dominava. Esse natural comportamento conquistou a admiração de todos os seus seguidores. Ela era a maior detentora de conhecimentos sobre as arboviroses no Brasil, e, considerando o total desses vírus sob seu domínio, que representava $1 / 3$ de todos os arbovírus existentes no mundo, também o era internacionalmente. Isso a transformava em grande referencial para consultas, dentro e fora do Brasil, mormente os isolados na Região Amazônica.

Em 1998, após 40 anos de serviços prestados a Amazônia, Amélia, a convite do Departamento de Patologia da University of Texas Medical Branch (UTMB), em Galveston, nos Estados Unidos, agregou-se a um grupo de pesquisadores, alguns dos quais considerados, como ela, expoentes na área de Arbovirologia, como os doutores Robert Shope e Robert Tesh. Em seus mais de 18 anos ininterruptos de atividades na UTMB, caracterizou centenas de vírus e publicou, em colaboração direta, cerca de 110 trabalhos científicos de alta relevância para a ciência mundial. Após sua aposentadoria, em abril de 2017, Amélia retornou para sua cidade natal.

Seu adeus repentino, em 4 de dezembro de 2017, deixou uma grande lacuna na ciência e na pesquisa. Por esse motivo, nosso profundo respeito e gratidão para com essa cientista, reconhecida mundialmente por seus méritos e pelo que produziu na sua extensa labuta realizada diuturnamente na descoberta de novos vírus, procedendo sem ferir, sem enganar ou tirar proveito daqueles que ensinou, primando continuadamente pela ética. E, mais ainda, pelo exemplo de ser humano, pelo carinho e respeito que dispensava a todos que a cercavam. Como Evandro Chagas, Amélia Travassos da Rosa não se apagará na poeira do tempo. Será lembrada sempre como uma "joia rara" a serviço da ciência. 